\title{
Analysis of a car door subjected to side pole impact
}

\author{
C. R. Long ${ }^{\mathrm{a}}$ (D)
}

\section{S. Chung Kim Yuen ${ }^{a *}$ (ic}

\section{G. N. Nurick ${ }^{a}$}

a Blast Impact and Survivability Research Unit (BISRU), Department of Mechanical Engineering, University of Cape Town, Rondebosch, 7701, South Africa. E-mail: crlong88@gmail.com, steeve.chungkimyuen@uct.ac.za, gerald.nurick@uct.ac.za

*Corresponding author

http://dx.doi.org/10.1590/1679-78255753

\begin{abstract}
The results of a study on the response of a side impact beam located in a car door to impact loading is presented. The side impact beam is situated in both the front and rear side doors of a vehicle between the inner and outer shells to minimise intrusion into the passenger compartment during a collision whilst absorbing as much impact energy as possible. A numerical model of a light-weight passenger car, developed by the National Crash Analysis Center (NCAC) of The George Washington University under a contract with the Federal Highway Administration (FHWA) and National Highway Traffic Safety Administration (NHTSA) of the United States Department of Transportation (US DOT), was used to simulate a side impact on the front side door using the LS-DYNA R7.1.1 explicit solver. The resulting deformation of the door from the full vehicle model was used to design an experiment for an impact test on a passenger door to validate the simulation of an equivalent numerical model. In the experiments, the car door was subjected to a drop mass of $385 \mathrm{~kg}$ from a height of $1.27 \mathrm{~m}$ so that the maximum deflection on the car door impact test would be of similar magnitude to the maximum deflection of the door in the simulation of the full car model. Drop test experiments on beams with square and round cross-sections were carried out to validate the equivalent finite element model. The side impact beam was isolated for limited geometric optimisation with a view to improving the crashworthiness of the vehicle. The optimised compound tube configuration performed better than the single tube configuration in terms of SEA (specific energy absorbed) and maximum deflection.
\end{abstract}

\section{Keywords}

Crashworthiness, Lateral Tube Impact, Side Impact, Energy Absorption

List of abbreviations

\begin{tabular}{cc}
\hline NCAC & National Crash Analysis Center \\
\hline FHWA & Federal Highway Administration \\
NHTSA & National Highway Traffic Safety Administration \\
US DOT & United States Department of Transportation \\
ABS & Anti-lock Braking System \\
TC & Traction Control \\
ASM & Active Stability Management \\
SPI & Synthetic Performance Indicator \\
FGT & Functionally Graded Thickness \\
SEA & Specific Energy Absorption \\
EA & Energy Absorption \\
CFE & Crash Force Efficiency \\
FMVSS214 & Federal Motor Vehicle Safety Standard 214
\end{tabular}




\section{INTRODUCTION}

The best protection against any impact would be no crash at all. However, with the ever-increasing number of vehicles on the road the risk of an accident occurring keeps on rising. According to the World Health Organization, WHO (2015) it is estimated that road injuries claimed almost 3300 lives each day. This was an increase from 2900 deaths a day at the turn of the 21st century thus making road accidents one of the top 10 leading causes of death worldwide as reported by the WHO (2014). Crashworthiness is the ability of the energy absorbing devices located in the structure of a vehicle to protect the cargo and/or occupants against life changing injuries or loss of life during an accident. The structures of the vehicle must be able to minimise intrusion into the occupant compartment while also minimising the peak acceleration of a passenger during a collision. The approaches used by automobile manufacturers to improve safety can be classified into two categories, active safety and passive safety. Examples of active safety include a good suspension, stiff chassis, and electronic safety assists like Anti-lock Braking System (ABS), Traction Control (TC), and Active Stability Management (ASM). Passive safety devices serve the purpose of reducing injury, or the likelihood thereof, in the event of a collision. Such examples include seatbelts and bolsters, airbags, and energy dissipative structures. An automobile collision comprises three stages, the first stage involves the collision between the vehicle and obstruction, during the second stage the occupants collide with internal parts of the car (i.e. airbag, seatbelt, and upholstery) and the third stage involves internal organs striking the skeletal structure of the human body. Fatal injury results from stages two and three.

Accidents occur in a wide range of scenarios affecting any part of the vehicle and the occupants. A great deal of attention has already been given to frontal impact protection as it is the most common mode of collision. However, according to Otte $(1990,1993)$ and Lau et al. $(1991)$ of all road accident related injuries $18 \%$ involve side impact type incidents, of which $35 \%$ causing injury are fatal in nature. It should be noted that it is more difficult to protect the occupants against side impact collisions, as there is less space for the vehicle structure to deform and crumple to absorb impact energy. During a side impact, the key component to protect the occupants of a vehicle is the door. A car door consists of an inner and outer steel shell. The door is typically reinforced with a high strength high plasticity steel side impact beam or corrugated steel structure that is placed between the inner and outer steel shells and spans the length of the door. When the obstruction strikes the car door it deforms and absorbs energy. The impact load is also transferred into the surrounding structure and channeled around the occupants. One of the key features of side impact beams are to reduce intrusion into the vehicle whilst dispersing energy and impact forces in the chassis. Depending on the type of vehicle, the car door may also include airbags.

Several studies have been reported on different configurations of side impact beams as they are one of the key energy absorbing members of the side door. These studies investigated the effect of foam filled tubes against hollow tubes, ribbed structures inside tubes, or varying thicknesses along the length of the tube. Strano et al. (2013) conducted research into the design and manufacture of AIMg1Si0.6 alloy foam filled anti-intrusion beams. Tube materials included aluminium, high speed steel and low carbon steel. All tubes were subjected to 3-point bend tests with cylindrical $\emptyset 20 \mathrm{~mm}$ punch, $150 \mathrm{~mm}$ span between supports and constant crosshead rate of $500 \mathrm{~mm} / \mathrm{min}$. Each specimen was deformed by a maximum of $48 \mathrm{~mm}$. This conformed to the side impact design guidelines from the Insurance Institute for Highway Safety, IIHS (2006). Square and circular tubes were tested, some hollow and others filled with foam. The circular low carbon steel and circular heat treated low carbon steel tubes were found to have the best trade-off between cost and Synthetic Performance Indicator (SPI). Ghadianlou and Abdullah (2013) numerically investigated the effect of adding different ribbed structures into circular tube cross-sections. The tubes were embedded within a side door and struck horizontally with a steel pole of mass $20 \mathrm{~kg}$ at $4 \mathrm{~m} / \mathrm{s}(14.4 \mathrm{~km} / \mathrm{h})$. The maximum deflection obtained from the results indicated that tubes with horizontal internal ribs performed better than their vertically ribbed counterparts. This may be attributed to a higher second moment of area about which bending occurred for the horizontally ribbed cells. The results also showed that more cells in the tube perform better, as with more cells there was more material to resist bending.

Sun et al. (2015) reported on the analysis and optimisation of the dynamic bending behaviour of circular Functionally Graded Thickness (FGT) tubes. The FGT tubes had varying thickness about the longitudinal centre with maximum thickness at the centre. The wall-thickness of the tube was varied as a function of position. The simple 3-point bend test was simulated in LS-DYNA. The thin walled tube, made from an aluminium alloy AA6061, was modelled using Belytschko-Tsay reduced integration shell elements with 5 through thickness integration points. The piecewise linear plasticity material model was used with rate effects ignored due to the rate insensitivity of aluminium as used by Teng et al. (2007). The supports were modelled as rigid materials whilst the tube material was characterised using a standard uni-axial tensile test. The FGT tubes were benchmarked against same weight uniform thickness tubes. A similar study using Functionally Graded Foam (FGF) in square tubes was conducted by Fang et al. (2014). Two grading patterns were assessed. Kriging (a probabilistic mathematical tool), and a Multi-objective particle optimisation algorithm were 
integrated to conduct an optimisation study. The tubes were struck with a cylindrical $\varnothing 50$ mm object of mass $128 \mathrm{~kg}$ at a velocity of $4.4 \mathrm{~m} / \mathrm{s}(14.4 \mathrm{~km} / \mathrm{h})$ at mid-span in a simply-supported configuration. The aluminium alloy AIMg0.5F22 tube walls were modelled with a bilinear elastic-plastic material model with strain hardening, to good agreement with experimental results. When compared with their uniform graded counterparts the FGF tubes perform better under lateral impact for Specific Energy Absorption (SEA), Energy Absorption (EA), and Crash Force Efficiency (CFE) but performed worse in maximum impact force.

Studies have also been conducted on square tubes with different boundary or clamping conditions, tube thicknesses and different loading rates, by Jing and Barton (1998). Lateral impact tests were experimentally conducted at velocities of up to $6 \mathrm{~m} / \mathrm{s}(21.6 \mathrm{~km} / \mathrm{h})$. DYNA3D, Hallquist (2006), was used to model the experiments to obtain the velocity and force time histories of the experiments. Results showed that the mode of deformation depended on the beam span and end conditions. The mode of deformation was found to be far more complex in thin-walled tubes as wrinkling would develop on the upper surface.

Studies to improve the performance of side impact beams with a view to minimize intrusion for better crashworthiness are ongoing. In this investigation, the results of a study carried out on the response of a side impact beam located in a car door to impact loading are presented. A numerical model of a light-weight passenger car was used to simulate a side impact on a front side door using the LS-DYNA R7.1.1 explicit solver. The resulting deformation of the door from the full vehicle model was used to design an experiment for an impact test on a passenger door to validate an equivalent numerical model. The side impact beam was isolated and subjected to drop test experiments to validate the equivalent finite element model. The side impact beam was isolated for optimisation with a view to improving the crashworthiness of the vehicle. Drop tests were carried out on beams with square and round cross-sections to validate the equivalent finite element model. A parametric study was conducted to optimize the side impact bar beam by changing its configuration whilst retaining the mass.

\section{RESEARCH METHODOLOGY}

This research work was divided into three parts:-

Part 1: Passenger car subjected to side impact loading - numerical simulations,

Part 2: A passenger car door subjected to impact loading - experiments and numerical simulations

Part 3: Side impact beams subjected to lateral impact loading - experiments and numerical simulations

A numerical model of a light-weight passenger car was used to simulate a side impact collision with a rigid vertical $273 \mathrm{~mm}$ diameter pole on the front side door at $8 \mathrm{~m} / \mathrm{s}(29 \mathrm{~km} / \mathrm{h})$ in close conformation to the Federal Motor Vehicle Safety Standard 214 (FMVSS214). The resulting deformation of the door from the full vehicle model was used to design an experiment for an impact test on a passenger door which was carried out in part two. The data from the experiment was used to validate the equivalent numerical model of the car door subjected to an impact load. The side impact beam in the door was identified and subsequently extracted from the door for further study. A set of drop test experiments were carried out on the square and circular tubes. The tubes were struck with a $200 \mathrm{~kg}$ mass released from heights ranging from 250 to $500 \mathrm{~mm}$ to validate an equivalent numerical model. Scanning Electron Microscopy was used to infer Young's Modulus for the tube material with similar composition from the literature. Lateral compression tests were carried out on sections of the tube to obtain the strength coefficient and hardening exponent for the power-law plasticity material model. Finally, a parametric study was undertaken on a compound tube configuration to minimize the transverse deflection.

\subsection{Part 1: Passenger car subjected to side impact loading - numerical simulation}

A numerical model of a light-weight passenger car, developed by the National Crash Analysis Center NCAC (2011) of The George Washington University under a contract with the Federal Highway Administration (FHWA) and National Highway Traffic Safety Administration (NHTSA) of the United States Department of Transportation (US DOT), was used to simulate a side impact collision with a rigid vertical $273 \mathrm{~mm}$ diameter pole on the front side door at $8 \mathrm{~m} / \mathrm{s}(29 \mathrm{~km} / \mathrm{h})$, using the LS-DYNA R7.1.1 explicit solver. The complete model consisted of 771 parts with a total of 974,383 elements. The model comprised a fully functioning suspension and steering subsystem, as well as all major structural components, but excluded any interior components or restraint systems. The element sizes of components were discretised in accordance with simulation processing time and accuracy relative to the rest of the vehicle. For example, the engine block was modelled as an isotropic hypo-elastic material with a comparatively coarse solid block mesh using hexa (brick) elements, as it remained largely undeformed in crashes relative to the rest of the vehicle. The windshield and door windows were modelled as a modified piecewise linear plasticity material without the inclusion of damage mechanics. 
The chassis was modelled with shell elements using the piecewise linear plasticity material model, and joined with spotwelds. The HAZ (Heat Affected Zone) of the spot-welds were accounted for by means of the spot-weld material definition in LS-DYNA. The tyres and damper joints were modelled as an elastic and nearly incompressible continuum material by Blatz and Ko (1962) respectively. Failure criteria were not set for any component definitions. Material data for all main mechanical components were obtained through testing of samples extracted from vehicle parts as implemented into the model by NCAC (2011).

The vehicle was propelled laterally into a $273 \mathrm{~mm}$ diameter rigid vertical pole at approximately $420 \mathrm{~mm}$ from the B-pillar as shown in Figure 1. The vehicle was assumed to be on a rolling sled with negligible mass such that the coefficient of friction between the tyres and ground was negligible. The simulation was conducted in close conformation to the FMVSS214 standard to determine the impact characteristics of the door. The FMVSS214 test specification requires that a 10 inch $(254 \mathrm{~mm})$ outer diameter pole be used. However, a $273 \mathrm{~mm}$ diameter rigid vertical pole was used in the experiment due to unavailability of materials. The FMVSS214 test specification also requires that the vertical pole be located such that the point of impact lines up within two transverse planes located $\pm 38 \mathrm{~mm}$ longitudinally of the centre of gravity of the crash test dummies head. The velocity vector of the vehicle should also line up within $\pm 3^{\circ}$ of the transverse plane of the centre of gravity of the vehicle US Department of Transportation (2016). This would have resulted in the pole lining up with the B-pillar. However, in this study the rigid pole was shifted so that the rigid pole impacted the door centrally to investigate the effectiveness of the door and its components to absorb impact energy.

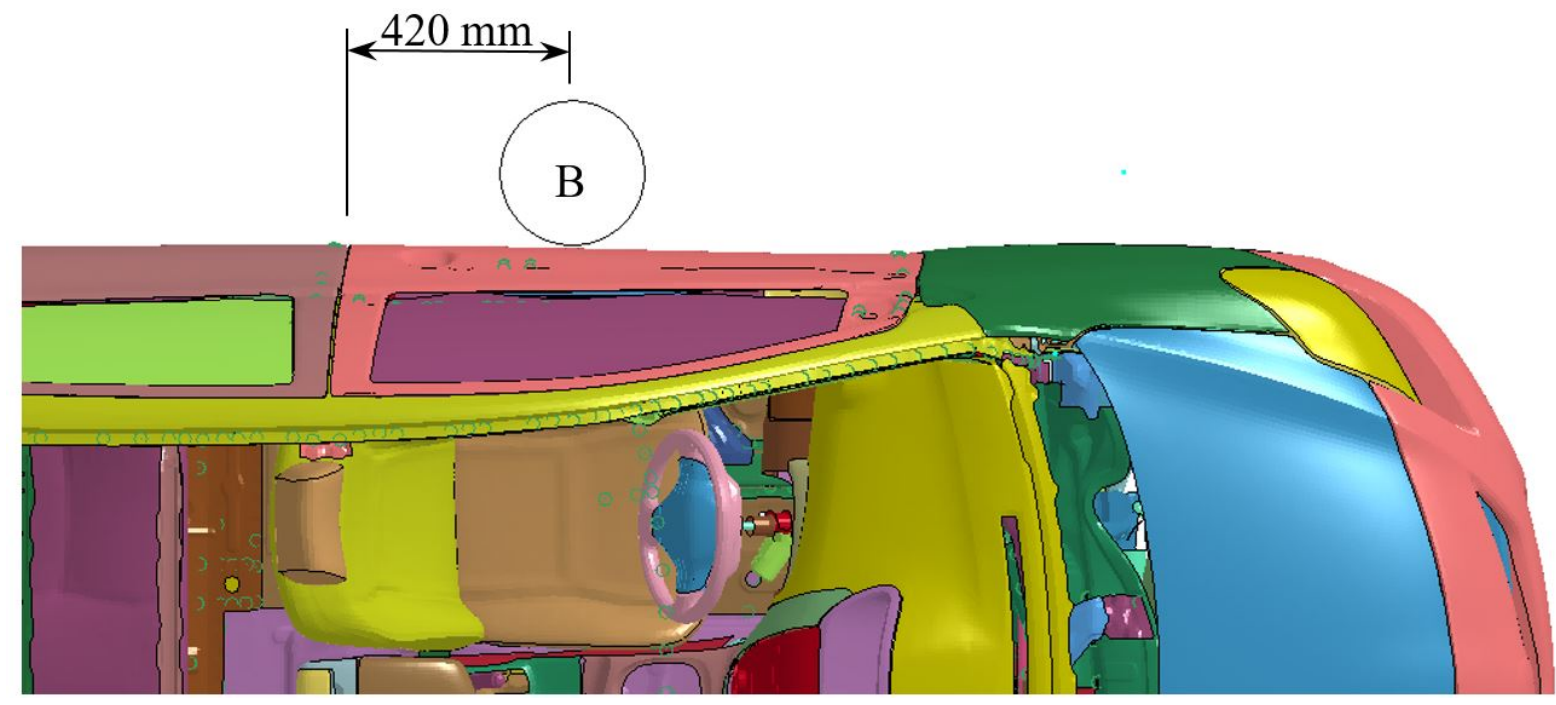

Figure 1: Position of Rigid Pole for the purpose of testing the Impact Bar's ability to absorb and deflect energy away from the occupants.

The underside of the vehicle at a time of $92 \mathrm{~ms}$ after impact is shown in Figure 2(a), and an isometric view of the simulation result is shown in Figure 2 (b). The side of the vehicle, as illustrated in Figure $2 s(c)$ and (d), was isolated from the rest of the vehicle to highlight the deformation of the door and its surrounding support structure.

The rigid pole caused deformation of the door, outer rocker panel, roof, floor, and windshield. The exhaust channel width indicated in Figure 2(a), reduced from $237 \mathrm{~mm}$ to $85 \mathrm{~mm}$ as a result of the impact. The vehicle, upon impact, appeared to roll into the vertical pole with the top of the car undergoing marginally higher deformation than the floor. This may be attributed to the presence of more material resisting deformation near the floor than in the roof, with the side impact beam in the bottom third of the door. A damage model was not included in any components, which resulted in ductile behaviour as observed in the windshield in Figure 2(b). The graphic in Figure 2(c) shows that most of the deformation occurred in the door, A-pillar and outer rocker panel. The illustration in Figure 2(d) shows the formation of a distinctive $\mathrm{V}$-profile of the door, as it wrapped around the rigid pole. The results also showed that the transverse deflection reached a maximum of $208 \mathrm{~mm}$ at $85 \mathrm{~ms}$ after the side impact beam began to deform. 


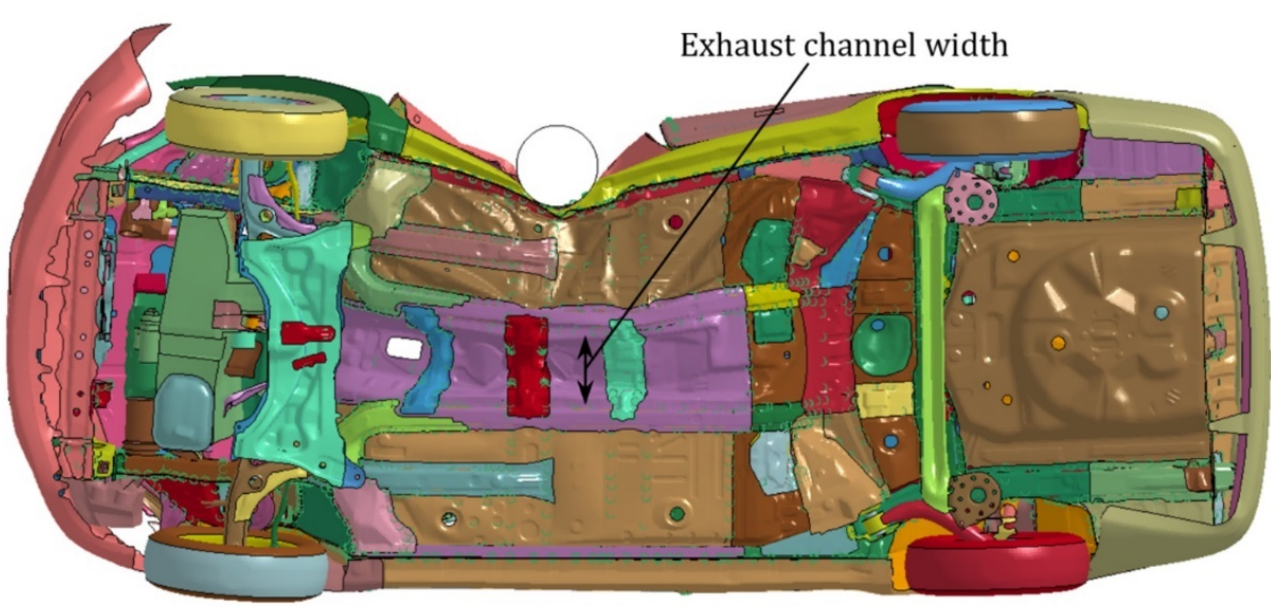

(a)

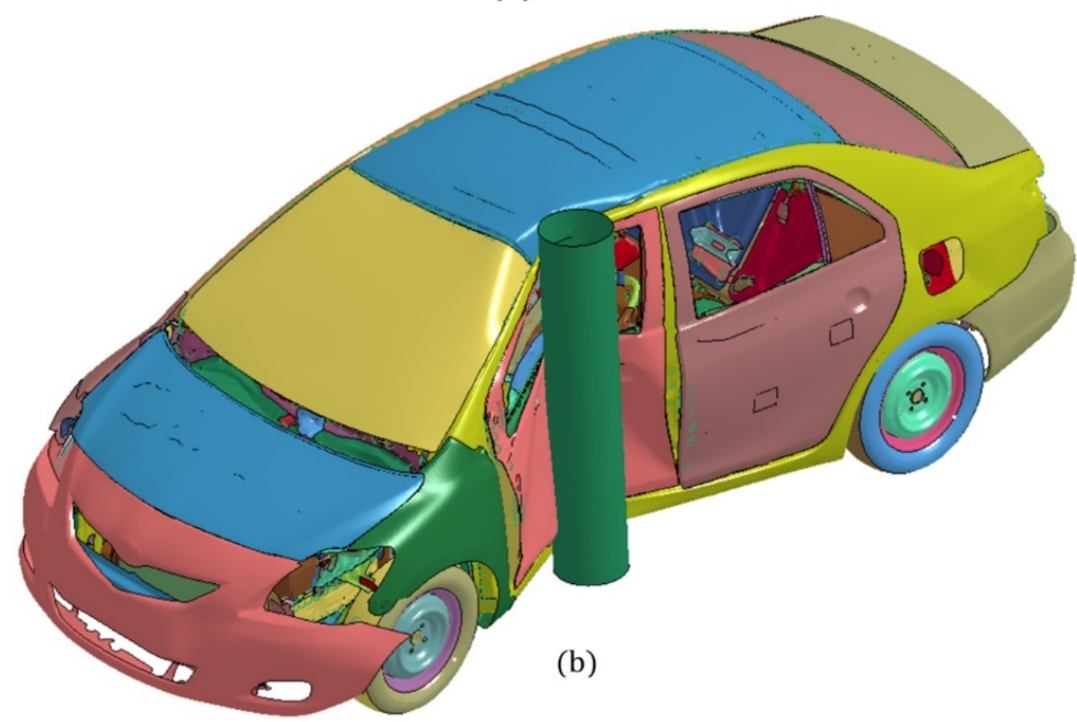

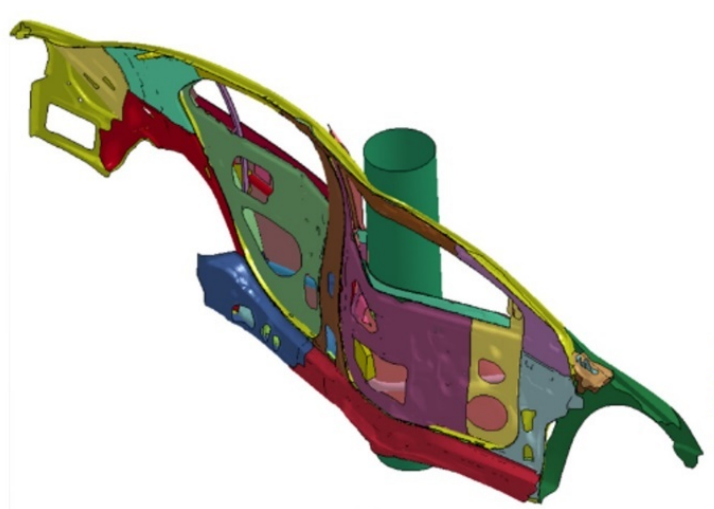

(c)

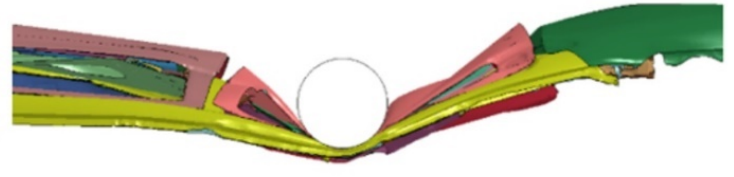

(d)

Figure 2: Side Impact Test of a 4-door sedan at $29 \mathrm{~km} / \mathrm{h}$ into a $273 \mathrm{~mm}$ diameter rigid vertical pole (a) bottom view with exhaust channel deformed, (b) isometric view of full vehicle, (c) isometric view of side of vehicle exposed to the rigid pole, and (d) top view where only the side exposed to impact is shown.

A breakdown of the distribution of energy absorbed in the side impact of the full vehicle model is shown in Figure 3. The four highest absorbers of energy, namely floor and roof panels, door and side impact beam, accounted for over three quarters of the energy absorbed. It should be emphasised that the side impact beam was one of the single highest energy absorbing components in this simulation. The tube absorbed $2.76 \mathrm{~kJ}$ of the total $33.1 \mathrm{~kJ}$. The bulk of the impact energy (66\%) was dissipated via bending of the sheet metal of the floor, roof and door panels. 


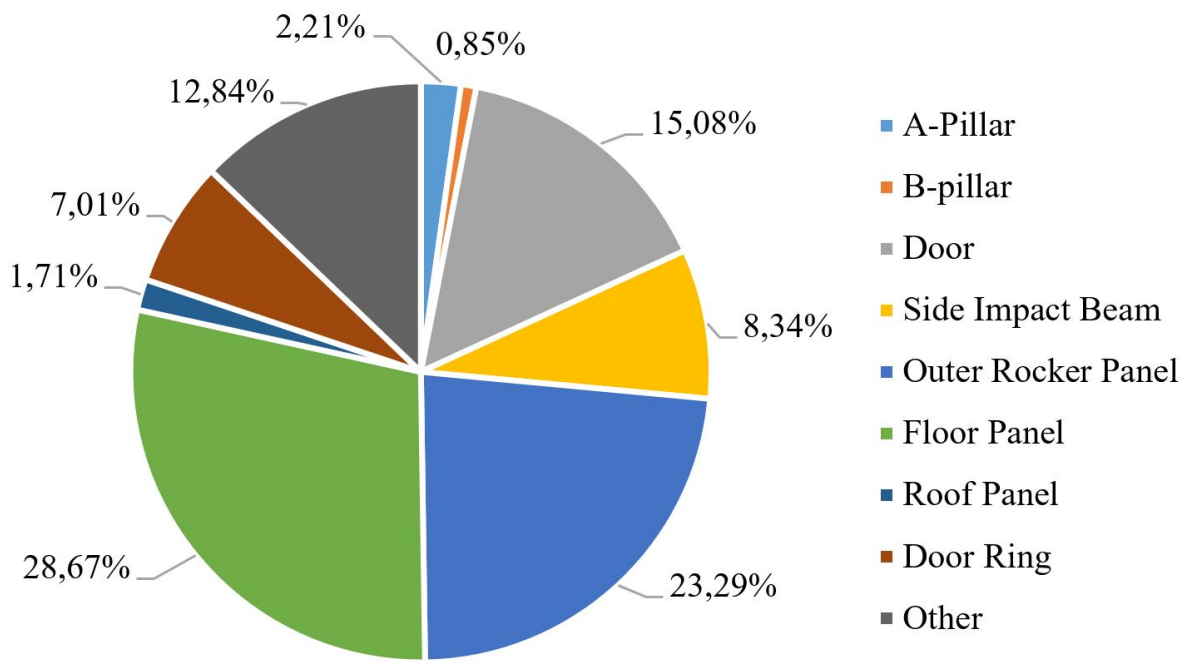

Figure 3: Breakdown of the largest contributing members to energy absorption in the side impact test of the full vehicle model in this study.

\subsection{Part 2: Passenger car door subjected to impact loading - experiments and numerical simulations}

The impact loading of the passenger car door experiment was designed based on the results for the temporal response of the side impact beam deflection from the full vehicle simulation using a simplified equivalent numerical model of the door. The data from the experiments was also used to validate the numerical model, shown in Figure 4, which comprised of two transverse pairs of $254 \mathrm{~mm} \times 146 \mathrm{~mm} \times 31.1 \mathrm{~mm}$ l-beam girders and $150 \mathrm{~mm} \times 150 \mathrm{~mm} \times 12 \mathrm{~mm}$ angle iron to allow for approximately $250 \mathrm{~mm}$ of overhead deflection of the trimmed door specimen. The door geometries were discretised using mixed quadrilateral and triangular shell elements. The Belytschko-Lin-Tsay shell element formulation with three through thickness integration points was used as it was found to be the most computationally efficient in solving transient non-linear natured problems as stated by Hallquist (2006). The material of the door was defined using the piecewise linear plasticity model. The strain-rate sensitivity was incorporated using the plastic kinematic hardening equations.

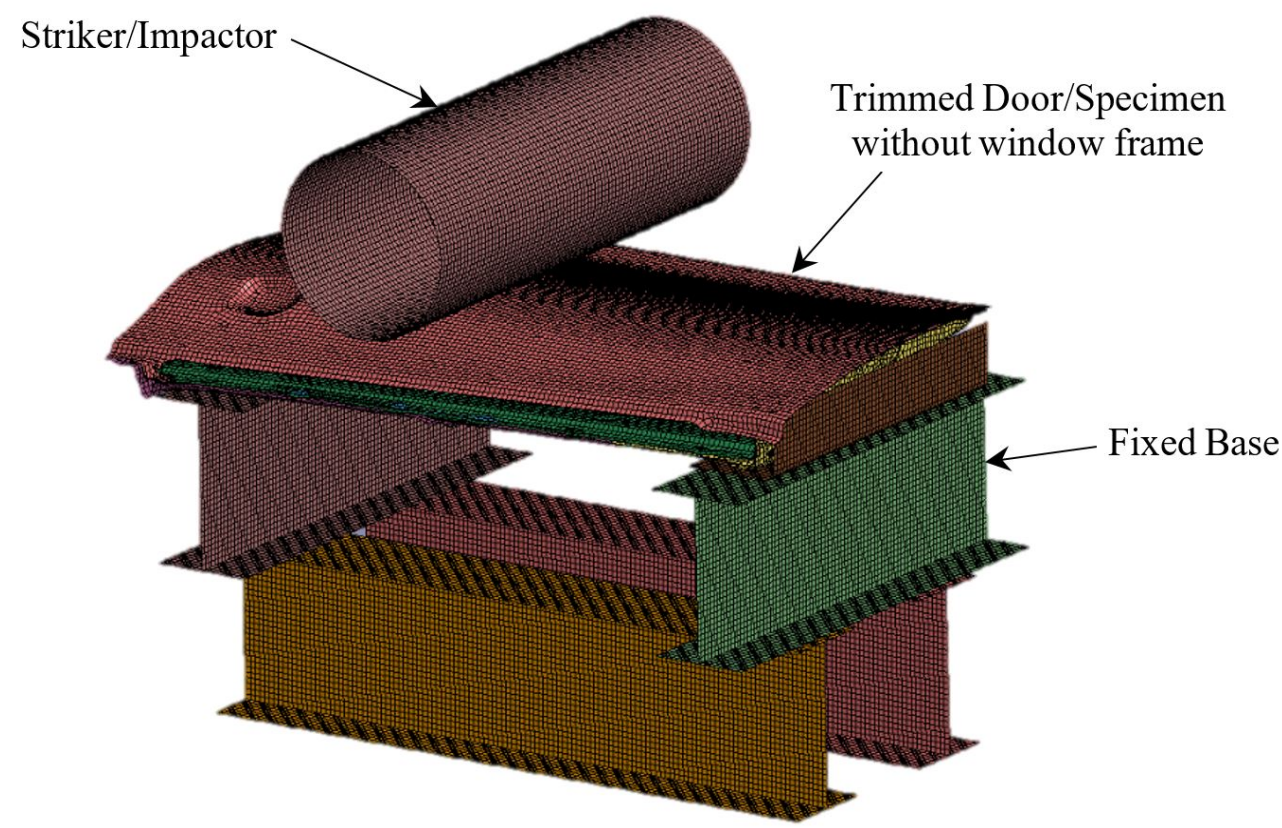

Figure 4: Numerical model of side door impact test rig with door of a passenger sedan mounted for testing.

The lower flanges of the bottom pair of I-beams were fully constrained as the I-beams were mounted onto a solid steel block in the experiments. The I-beams and angle iron were modelled with tied nodes at bolted connections, and automatic surface to surface contact cards were defined for all contacting steel work. Static and dynamic friction 
coefficients of 0.57 and 0.74 , obtained from Ramsdale (2004), were defined for all steel to steel contacts respectively. The rate of deformation of the door was matched by first varying the impact velocity of the striker, and the magnitude of maximum deformation was achieved by varying the mass of the striker.

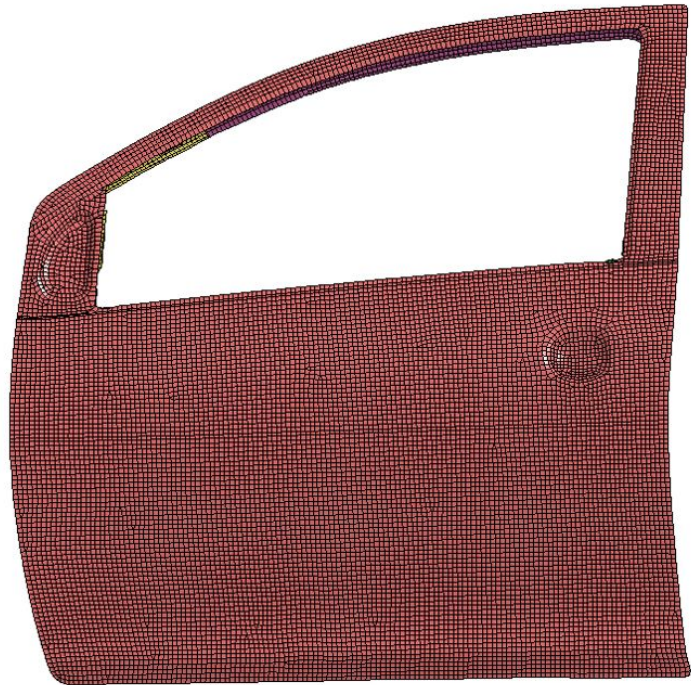

(a)

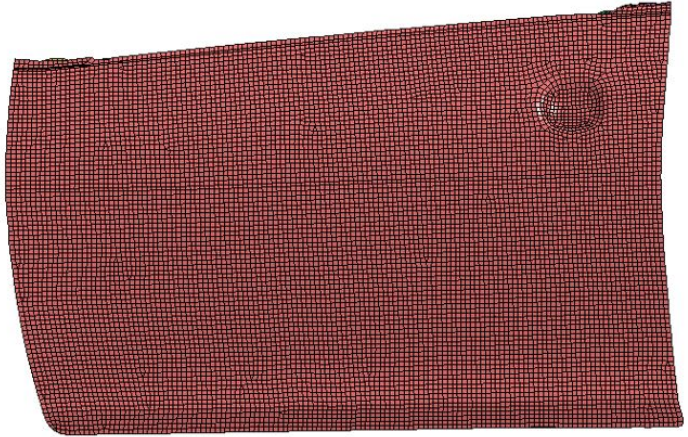

(b)

Figure 5: (a) Door model extracted from full car model, and (b) modified door model to exclude top frame to simulate experiments

Due to spatial limitations in the test rig, the car door, shown in Figure 5(a) was modified. The top frame was removed prior to testing as shown in Figure 5 (b). One of the key energy absorbers located inside the car door is the side impact beam. The deflection of the door was quantified in terms of the deflection of the side impact beam. A cylindrical impactor weighing $390 \mathrm{~kg}$ with impact velocity of $4.8 \mathrm{~m} / \mathrm{s}(17.3 \mathrm{~km} / \mathrm{h})$ was found to produce the most representative deflection time histories of the door with frame in the full vehicle simulation. A numerical comparison of the response of a door with frame and without a frame to the side impact loading was carried out. The deflection of the side impact beam from the door with frame and without a frame is shown in Figure 6. The maximum deflection of the side impact beam in the door model with frame was measured at $208 \mathrm{~mm}$ which was similar in magnitude compared to the side impact beam from the full vehicle model. The deflection of the side impact beam in the door model without frame was found to be $3 \mathrm{~mm}$ more at $211 \mathrm{~mm}$. The removal of the frame from the door therefore only amounted to a $1.4 \%$ increase in deflection of the side impact beam.

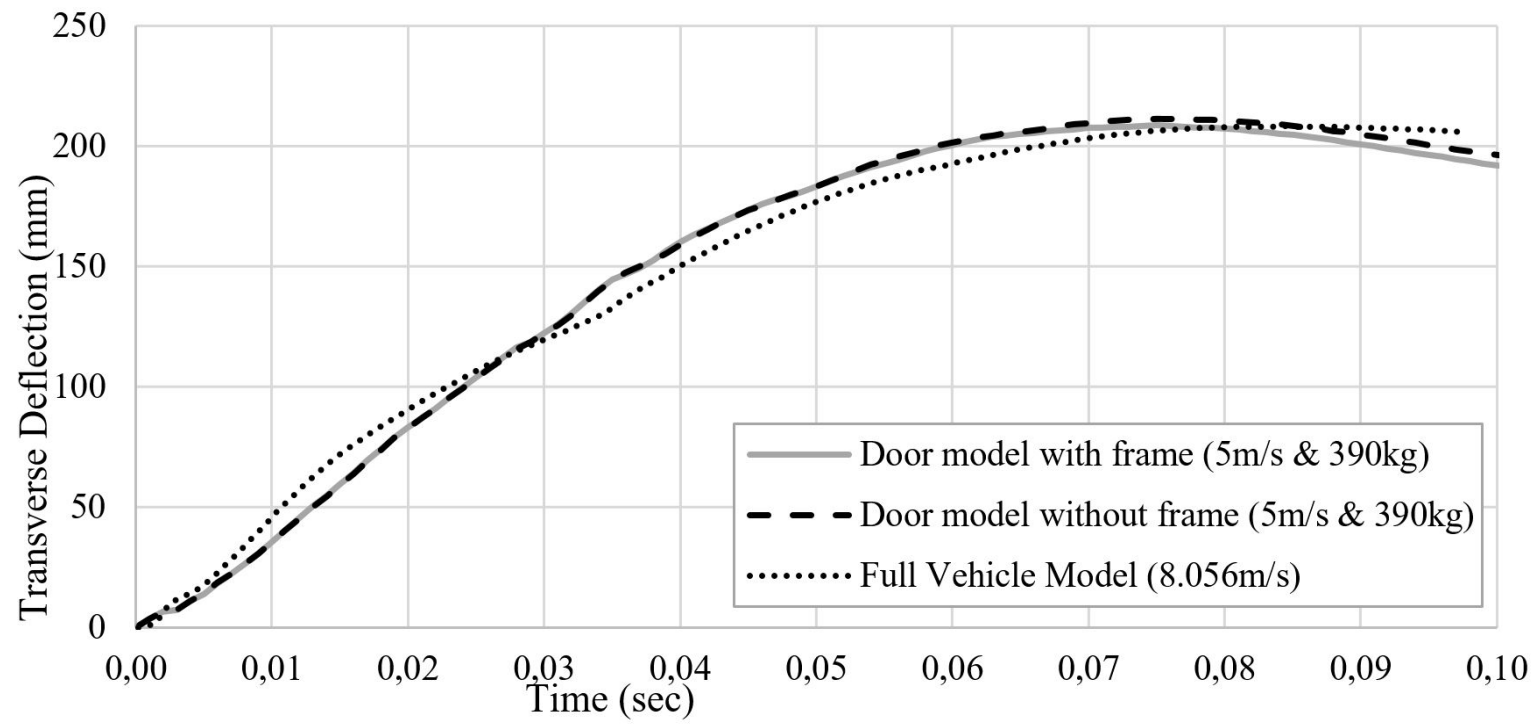

Figure 6: Comparison of transverse deflections of the side impact beam in the door model with and without the top frame of the door, together with the transverse deflection of the side impact beam in the full vehicle model 
The experimental setup of the door test rig after installation is shown in Figure 7. The spatial limitations due to the framework of the drop tester requiring the removal of the top frame of the door can be observed in Figure 7(a). The drop mass was reduced from $390 \mathrm{~kg}$ to $385 \mathrm{~kg}$ in the experiment to account for the approximate 1-1.5\% reduction in the doors ability to absorb energy due to the removal of the door top frame. The experiments were recorded using a GoPro Hero 4 Black Edition camera at $120 \mathrm{fps}$ (frames per second).

Figure 8 shows a time lapse of five image frames from footage of the drop test. Image Frame 0 (Figure 8(b)) shows the motion blur induced in combination by a moving striker and low frame rate of approximately $4.5 \mathrm{~m} / \mathrm{s}$ and $120 \mathrm{fps}$ respectively prior to impact. Image Frames 11, 29 and 132 show the drop mass impacting the door and rebounding. The results from the simulation of the drop test were in good agreement with the experiment in terms of the temporal response of the striker shown in Figure 9. The maximum displacement of the striker from the experiment and simulation were $266 \mathrm{~mm}$ and $268 \mathrm{~mm}$ respectively.

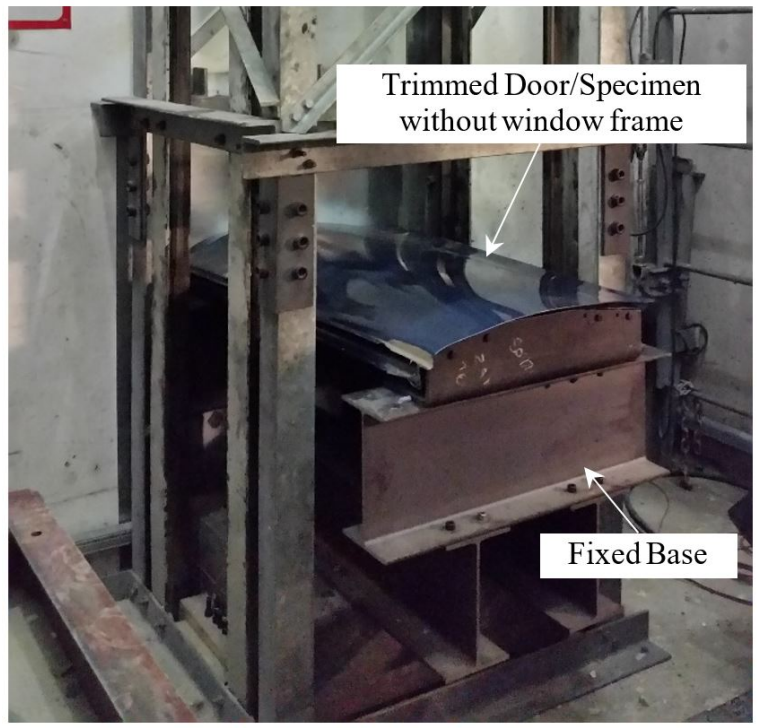

(a)

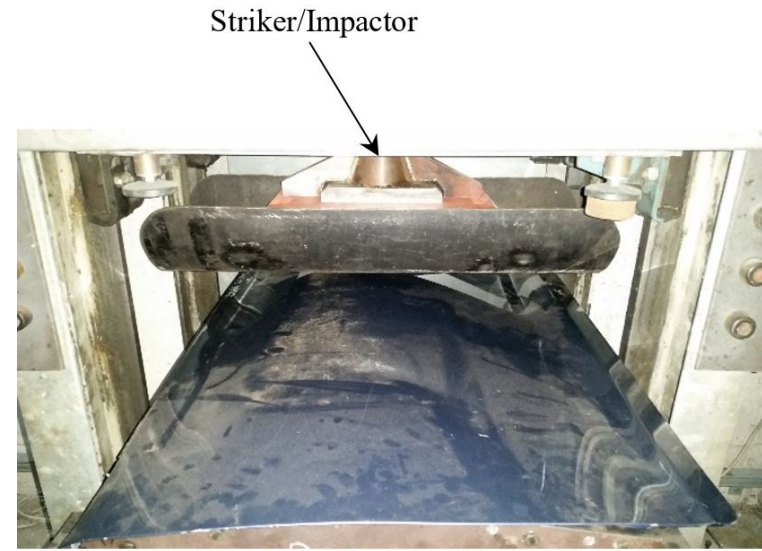

(b)

Figure 7: Side door impact test rig with door of a passenger sedan mounted for testing.
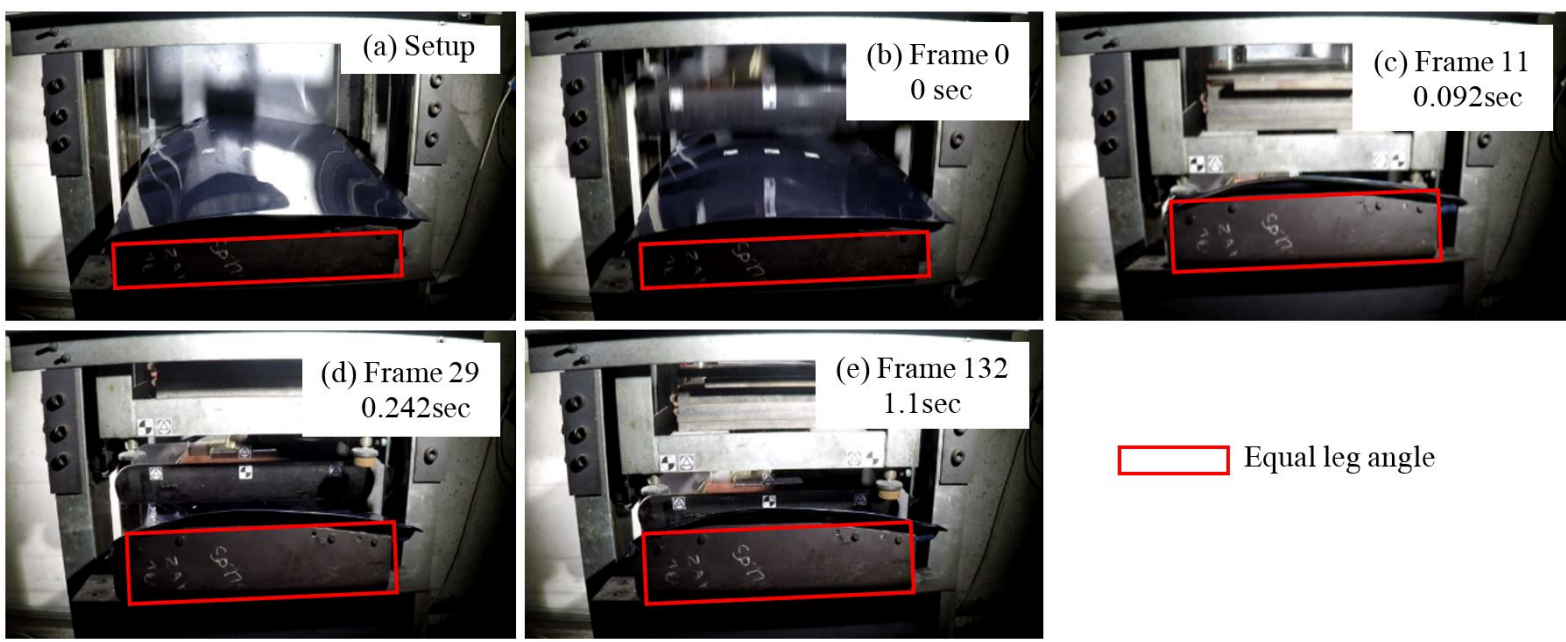

Figure 8: Time lapse of drop test experiment, (a) before impact, (b) at the last frame before contact between the striker and door occurs, (c) at maximum deflection, (d) first rebound, (e) striker is at rest. Frame Rate $=120 \mathrm{fps}$. 


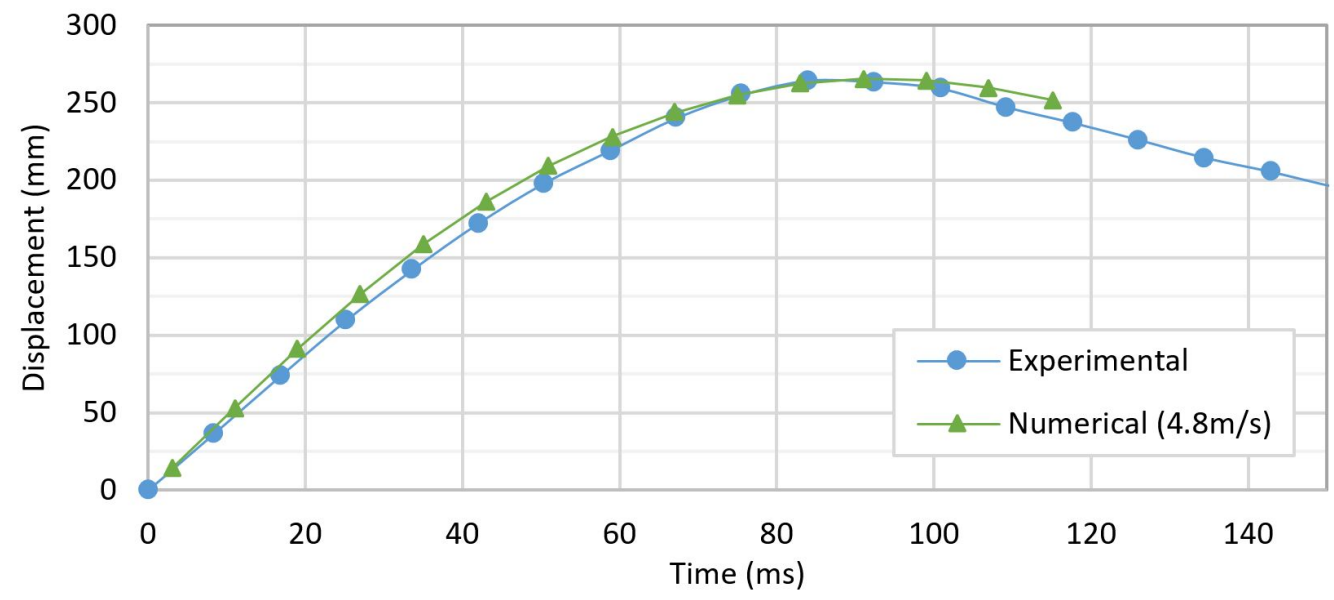

Figure 9: Comparison of numerical and experimental displacements of the $385 \mathrm{~kg}$ striker for the door test rig.

\subsection{Part 3: Side impact beams subjected to lateral impact loading - experiments and numerical simulations}

The side impact beam was identified as one of the key energy absorbers. A simplified side impact beam model was created based on the results of the car door drop test. Lateral impact tests of square and circular tubes were carried out to validate the finite element model. Material characterisation was undertaken on the square and circular tubes to determine their respective mechanical properties for use in the side impact beam model validation. Finally, a parametric study and numerical optimisation of a compound tube configuration was undertaken to minimise the deflection of the tube under impact loading similar to what it would experience in a side impact collision.

\subsubsection{Material characterisation of side impact beam for calibration of beam model}

Material characterisation was undertaken to determine the mechanical properties of the tubes for the side impact beam model. The composition of the material was obtained by means of Scanning Electron Microscopy. Young's Modulus was inferred from the literature for material with a similar composition. Quasi-static lateral compression tests of section of the tubes were carried out to identify the yield strength of the material. The experimental arrangement for the quasistatic lateral compression test is shown in Figure 10. The stress-strain curve, obtained from the quasi-static lateral compression test, is shown in Figure 11 for both square and circular welded seam tubes. The compression test was carried out at a crosshead speed of $5 \mathrm{~mm} / \mathrm{min}$, and the power-law plasticity model, given in equation 1, was fitted to the curve. It was assumed that the welded seam did not significantly affect the results as failure in the form of tearing was not observed in the seam.

$\sigma_{y}=k \varepsilon^{n}=k\left(\varepsilon_{y p}+\bar{\varepsilon}^{p}\right)^{n}$

Using the software LS-OPT in conjunction with LS-Dyna a linear polynomial metamodel with full factorial D-Optimal design point selection optimisation was implemented to find the strength coefficient $k$ and hardening exponent $n$. $A$ mean square error on the ordinate values of the force deflection histories of the experimental and numerical results were used as the objective function and optimised using the Adaptive Simulated Annealing optimisation algorithm. The strain-rate sensitivity was incorporated using the plastic kinematic hardening equations proposed in the CowperSymmonds model. The plastic kinematic hardening equation scales the yield stress in accordance with the strain rate as per equation 2. It was best suited for modelling isotropic and kinematic hardening. The rate parameters were obtained from literature based on the material type found from the Scanning Electron Microscopy results.

$\sigma_{y}=\sigma_{0}\left[1+\left(\frac{\dot{\varepsilon}}{C}\right)^{1 / p}\right]$

where $\sigma_{0}$ is the quasi-static yield stress, and the terms $\mathrm{C}$ and $\mathrm{p}$ are experimentally determined constants. 


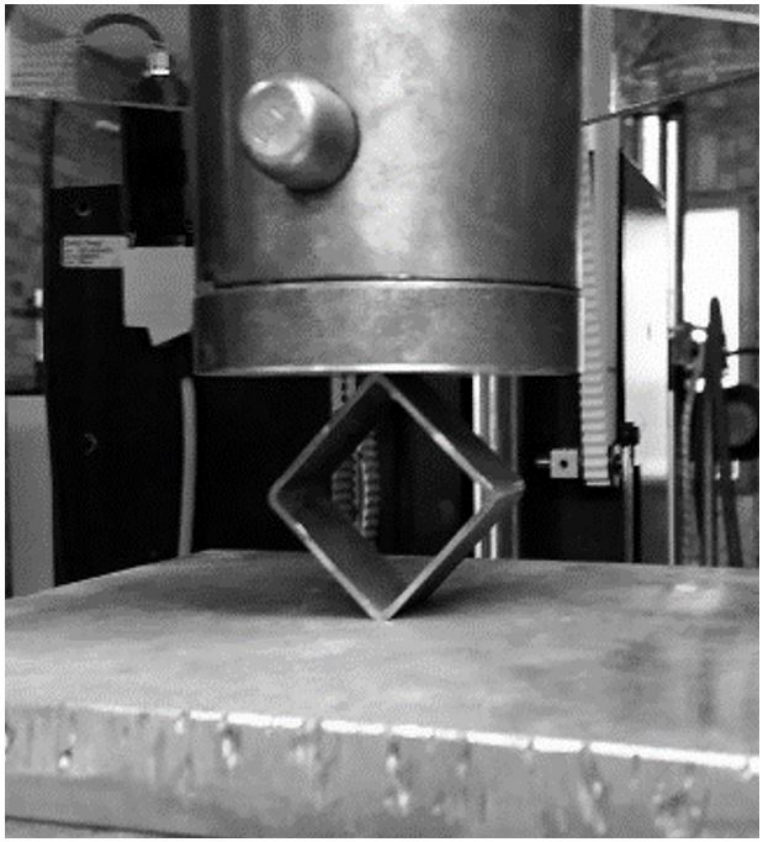

(a)

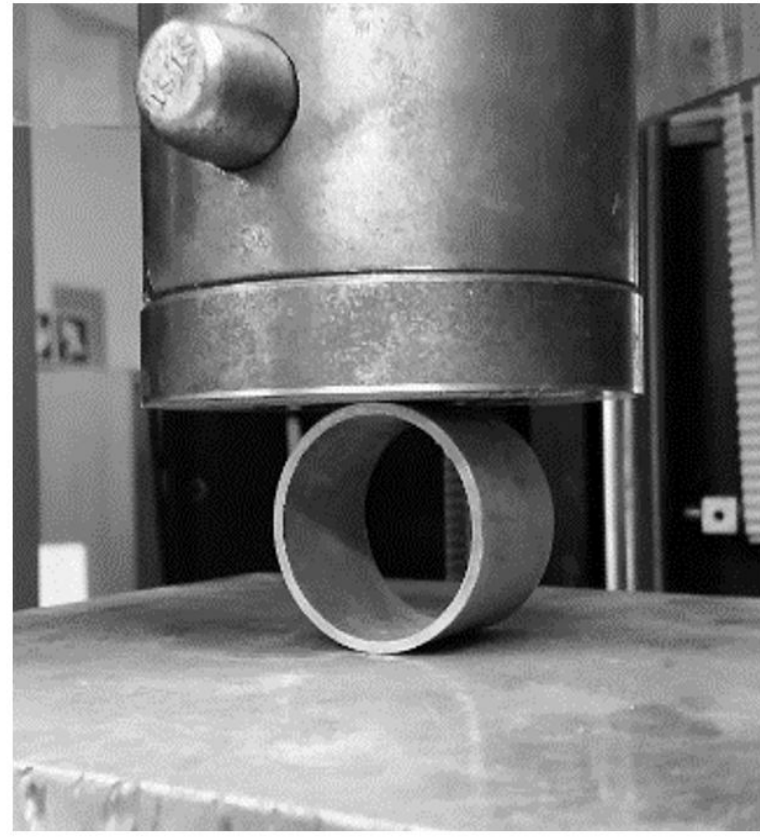

(b)

Figure 10: (a) $30 \mathrm{~mm}$ length of $40 \times 2.0 \mathrm{~mm}$ square and (b) $\varnothing 43 \times 2.3 \mathrm{~mm}$ round tube specimens in Zwick tensile testing machine prior to lateral compression.

The power-law plasticity material model was calibrated from the results of quasi-static lateral compression tests performed using a material testing machine. The results for the strength coefficients $(k)$ and hardening exponents ( $n$ ) for the square and circular tube materials are given in Table 1. The optimised load curves for the square and circular tubes obtained from the numerical simulations superimposed on the experimental results with machine compliance removed is shown in Figure 11(a) and (b) respectively.
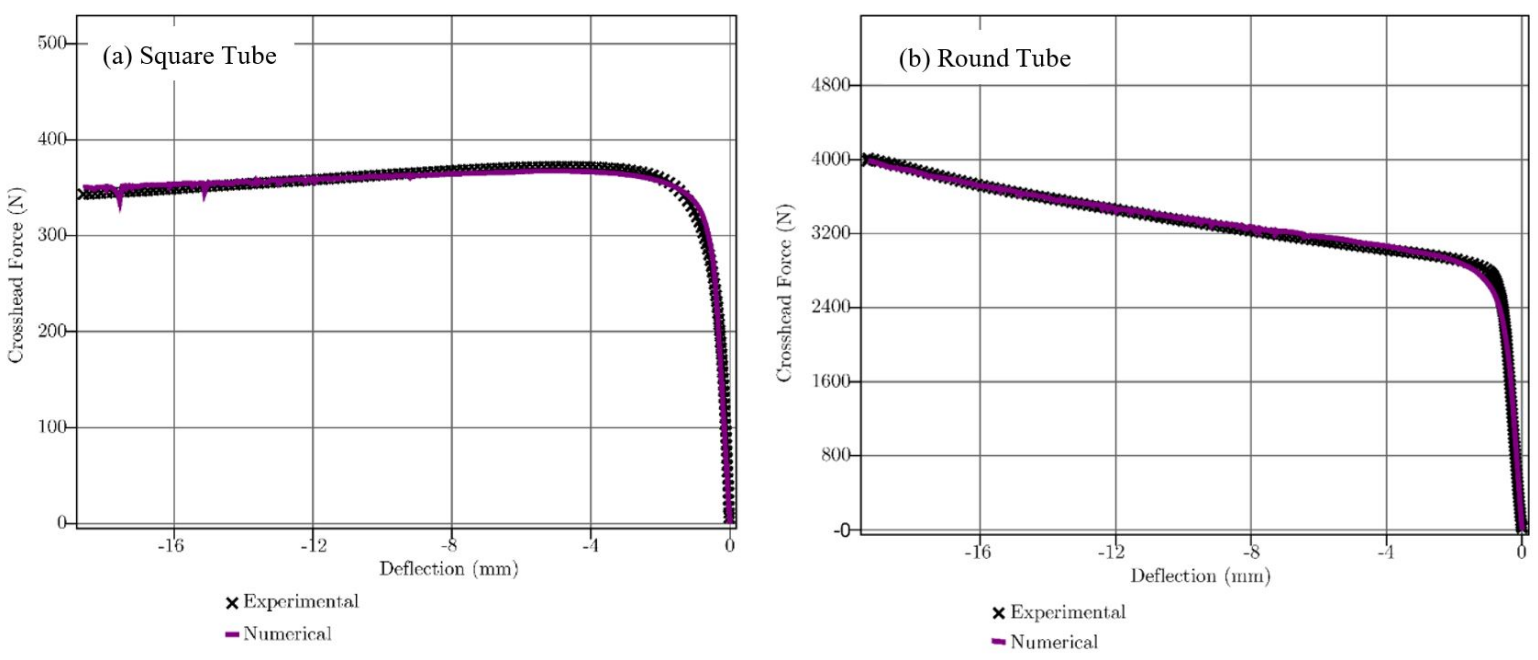

Figure 11: (a) Square tube Numerical \& Experimental Force versus displacement curves for k=335 MPa and n=0.065, and (b) Circular tube Force versus displacement curves for $\mathrm{k}=472 \mathrm{MPa}$ and $\mathrm{n}=0.078$.

Table 1: Result of lateral compression material characterisation study on the square and circular tube materials

\begin{tabular}{ccc}
\hline Material & $\begin{array}{c}\text { Strength Coefficient } \\
\text { k (MPa) }\end{array}$ & Hardening Exponent \\
Square Tube & 335 & 0.065 \\
Circular Tube & 472 & 0.078 \\
\hline
\end{tabular}




\subsubsection{Side impact beam experiments for validation of equivalent beam model}

A $200 \mathrm{~kg}$ mass was dropped from heights of $250,300,350,400,450$ and $500 \mathrm{~mm}$ to strike the tubes using the same shape striker as used in the car door drop tests. The tubes were struck at the same point along the length of the tube as in the door drop test and full vehicle side impact simulation. This striking point was at approximately one third of its span, measured from the translationally constrained end. The side impact beam test rig, shown in Figure 12, was built on the base of the door test rig. The test apparatus comprised two support mountings, one bolted pivot and one hinged Teflon collar as illustrated schematically in Figure 12(b). The bolted end was a translational constraint with one rotational degree of freedom, and the hinged Teflon collar allowed for the tube to slide axially and rotate about one axis at the other end. The tube drop tests were used to validate the side impact beam model through experimentation.

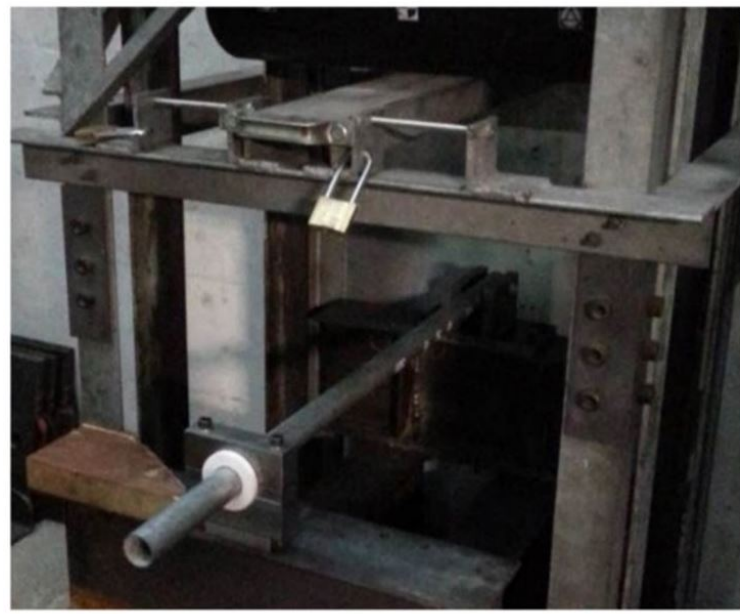

(a)

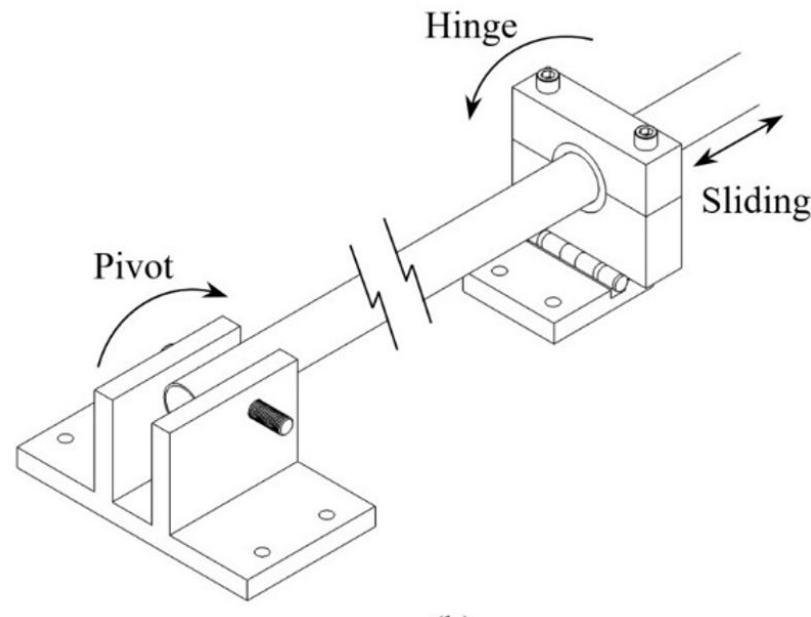

(b)

Figure 12: Experimental setup of side impact beam test rig with circular tube test specimen installed (a) photographic, and (b) schematic illustration.

The deformed square and circular tubes from the experiments are shown in Figures 13 and 14 respectively. Localised buckling in the impacted region was observed in all tests for both square and circular tubes. The impact tests from greater drop heights resulted in larger deflections and greater buckling angles. This was expected as more energy was absorbed with larger deflections. The side of the tube in the buckling region bulged outwards while the top face indented. The deformation pattern of the square tubes were similar to that of the circular tubes. A plot of the maximum deflections versus impact velocities for the square and circular tubes is shown in Figure 15. The trends of the square and circular tubes were similar, with transverse deflection increasing with increasing impact velocities. Quadratic trend lines, with an R-square value of 0.92 and 0.97 , were obtained for the square and circular tubes respectively because of the square velocity relationship with drop height. The results also indicated that for impact velocities higher than $2 \mathrm{~m} / \mathrm{s}(7 \mathrm{~km} / \mathrm{h})$ the square tubes performed better in terms of transverse deflection.

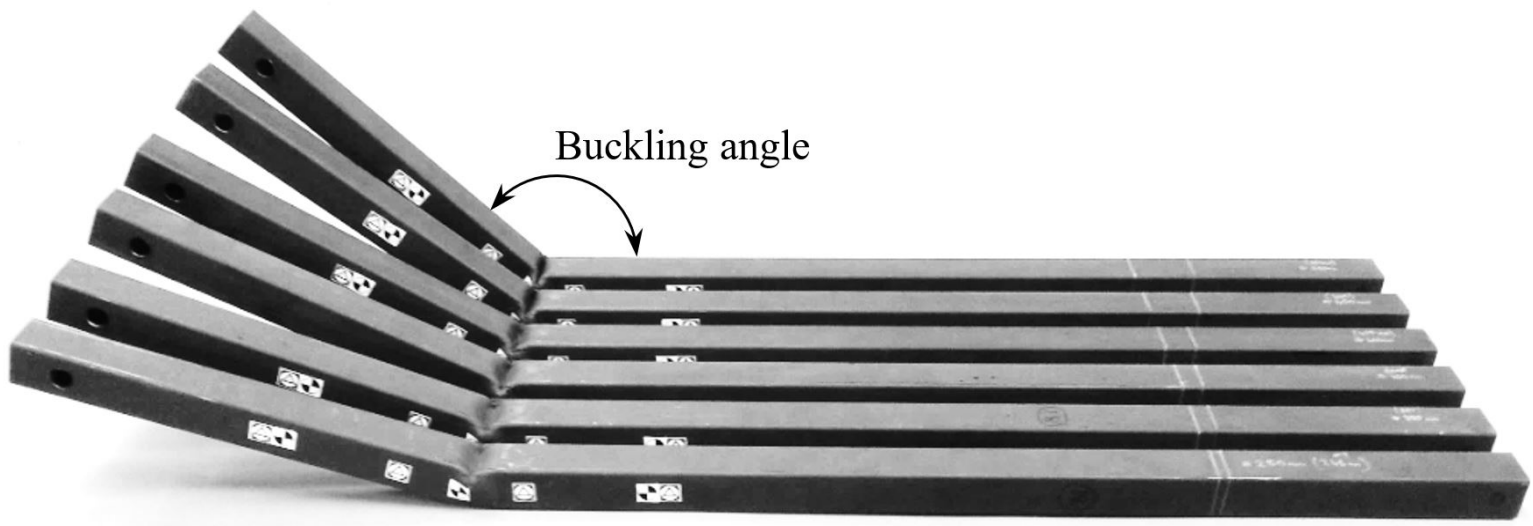

Figure 13: 40x2.0 mm Square Tube Drop Test results from drop heights between 250-500 mm. 


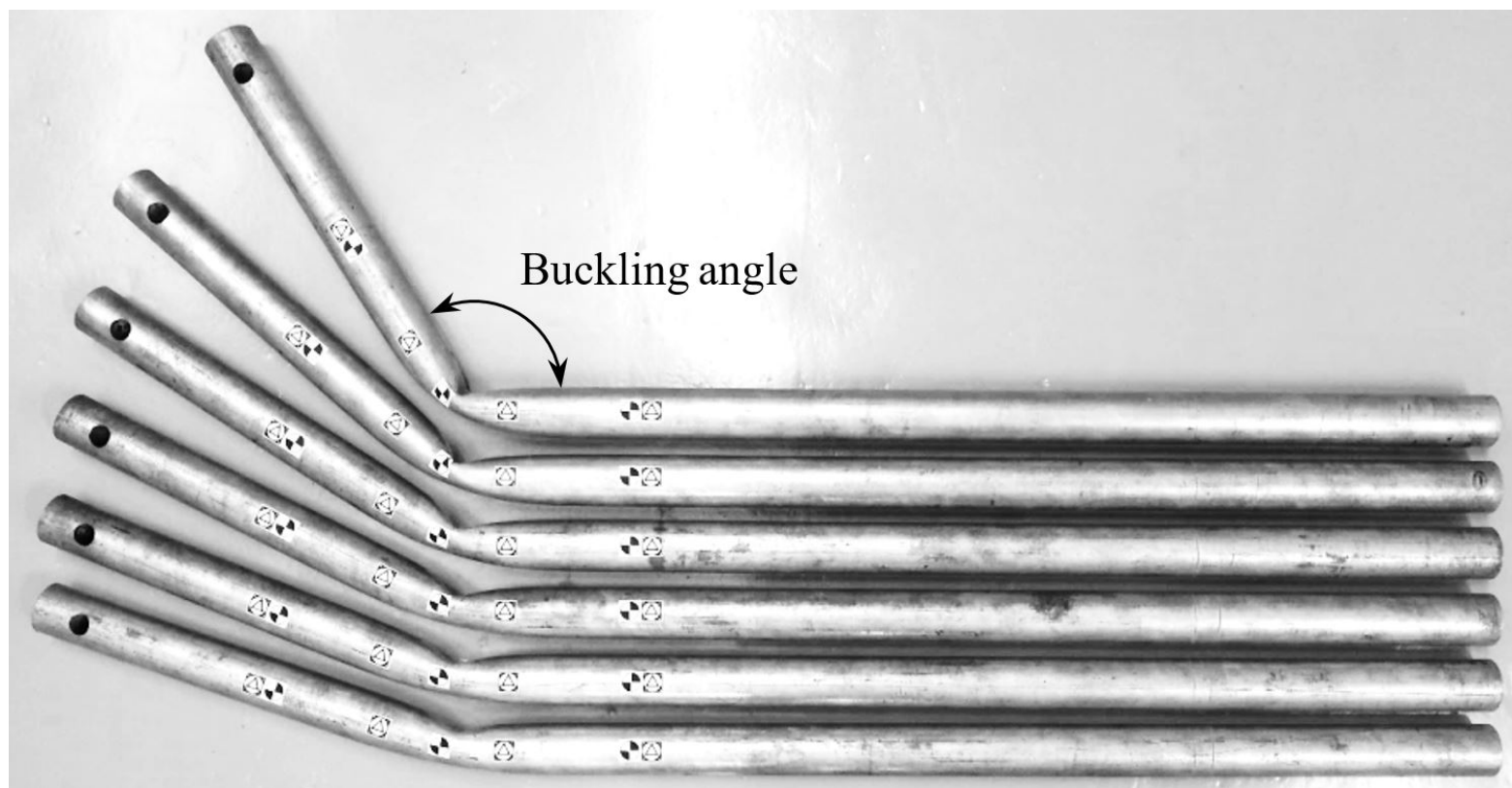

Figure 14: $\varnothing 43 \times 2.3 \mathrm{~mm}$ Circular Tube Drop Test results from drop heights between $250-500 \mathrm{~mm}$.

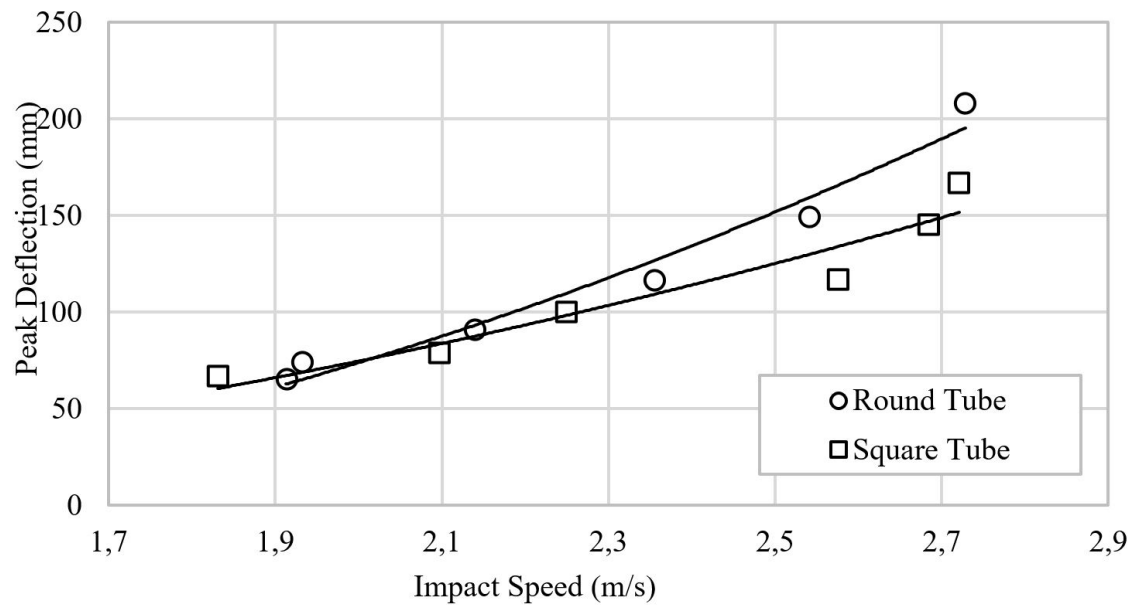

Figure 15: Graph showing the results obtained for the transverse deflection of a $40 \times 2.0 \mathrm{~mm}$ Square and $\varnothing 43 \times 2.3 \mathrm{~mm}$ Circular Tube subjected to lateral impact of a $200 \mathrm{~kg}$ mass dropped from different heights

An explicit finite element model with shell elements containing six through thickness integration points and a fully integrated quad and tri element formulation was used to simulate the side impact beam. The model provided the transient response of the square tube subjected to an impact from a 200kg drop mass at velocities ranging between $1.8-2.8 \mathrm{~m} / \mathrm{s}(6.5-10 \mathrm{~km} / \mathrm{h})$. The striker, endplate and pillow block were modelled as rigid materials to keep computational times to a minimum. The numerical model for square tube is shown in Figure 16. The striker was modelled as a $1 \mathrm{~mm}$ thick shell with scaled density for a mass of $200 \mathrm{~kg}$. Gravity was also added to the model in the y-direction. The endplate was an idealisation of an M16 bolted pivot, where the bolt was lightly greased to facilitate free rotation. One node in the centre of the endplate was constrained about all degrees of freedom except the rotational $x$-axis to impose the bolted pivot boundary condition. The pillow block was free to rotate about its pivoted edge. An automatic surface to surface contact was used between the striker and tube, pillow block and Teflon insert, as well as Teflon insert to tube. Nodes were merged between the endplate and tube enabling a rigid coupling. 


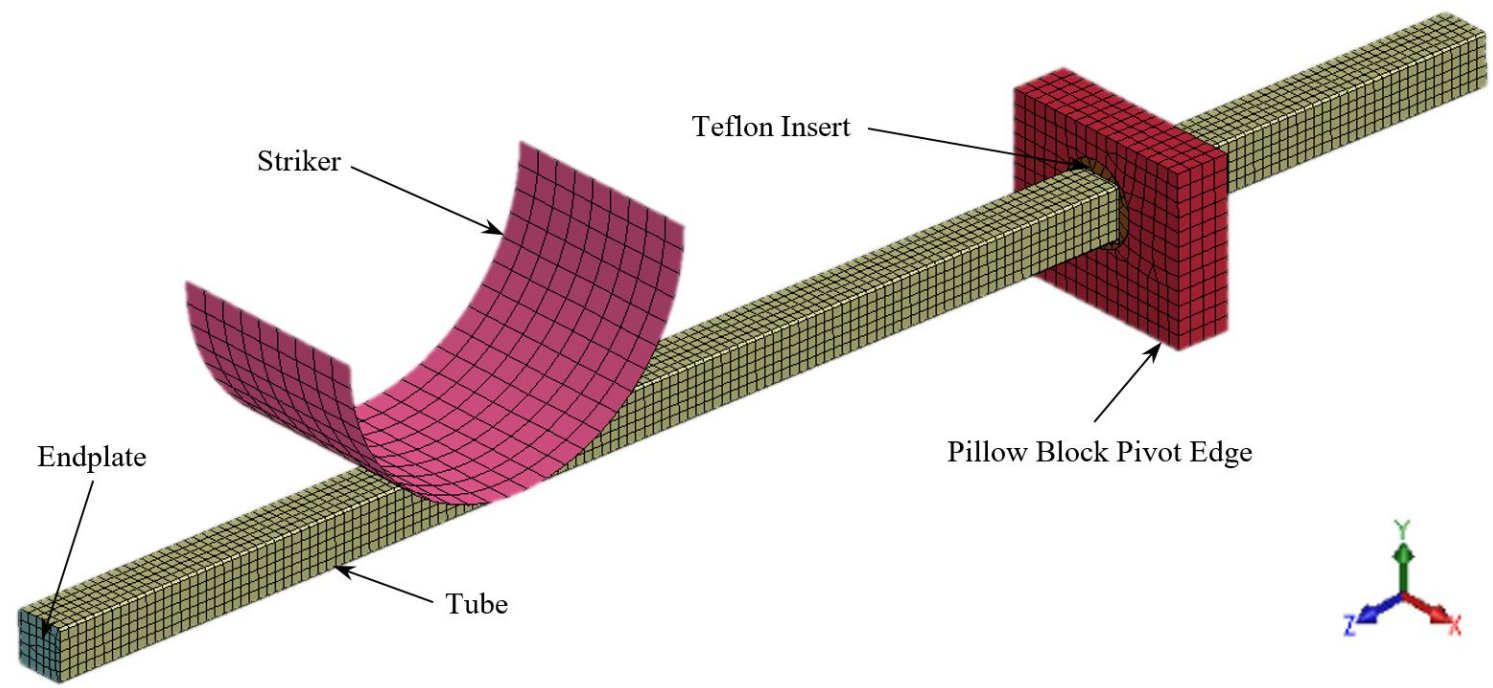

Figure 16: Finite element model of the $40 \times 2.0 \mathrm{~mm}$ Square tube $(6.9 \mathrm{~mm}$ mesh spacing) side impact beam.

A study was conducted on the side impact beam model to determine the coefficient of friction which produces results in best agreement with the experimental transient time histories of the deflection corresponding to each drop test. It was found that a coefficient of friction of 0.5 best fit the data with results from the higher drop heights more sensitive to the friction coefficient than lower heights. A sample of the comparison between the experimental and numerical results for the transverse deflection of the square tube, in which the striker was dropped from a $250 \mathrm{~mm}$ height, is shown in Figure 17. The numerical and experimental displacement-time histories were differentiated for the drop test from a height of $250 \mathrm{~mm}$ to produce the velocity-time histories also shown in Figure 17 . The velocity was at its maximum of approximately $2 \mathrm{~m} / \mathrm{s}$ immediately after contact was established between the striker and tube. There was noise/ringing of the impact velocity in the first $30 \mathrm{~ms}$ after impact for the velocity-time history of the experimental results. This was amplified upon differentiation to produce the acceleration-time histories shown in Figure 18 . The deceleration was fairly constant at $20 \mathrm{~m} / \mathrm{s}^{2}$ throughout the duration of impact.

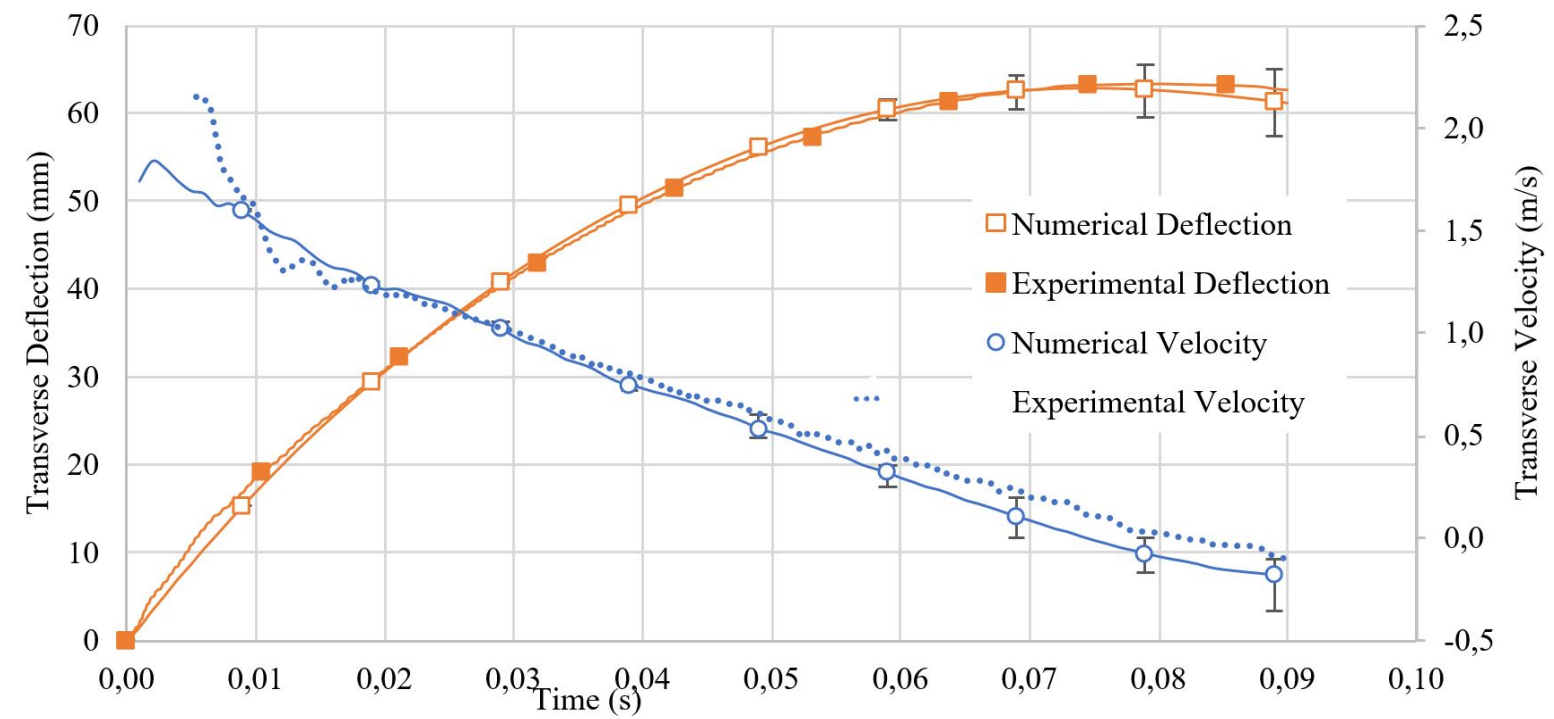

Figure 17: Graph showing the numerical versus experimental temporal deflection and velocity histories of square tube drop test from a height of $250 \mathrm{~mm}$, with plotted friction coefficient of friction of 0.50 and error bar indicating the effect of changing the friction coefficient to 0.30 or 0.74 . 


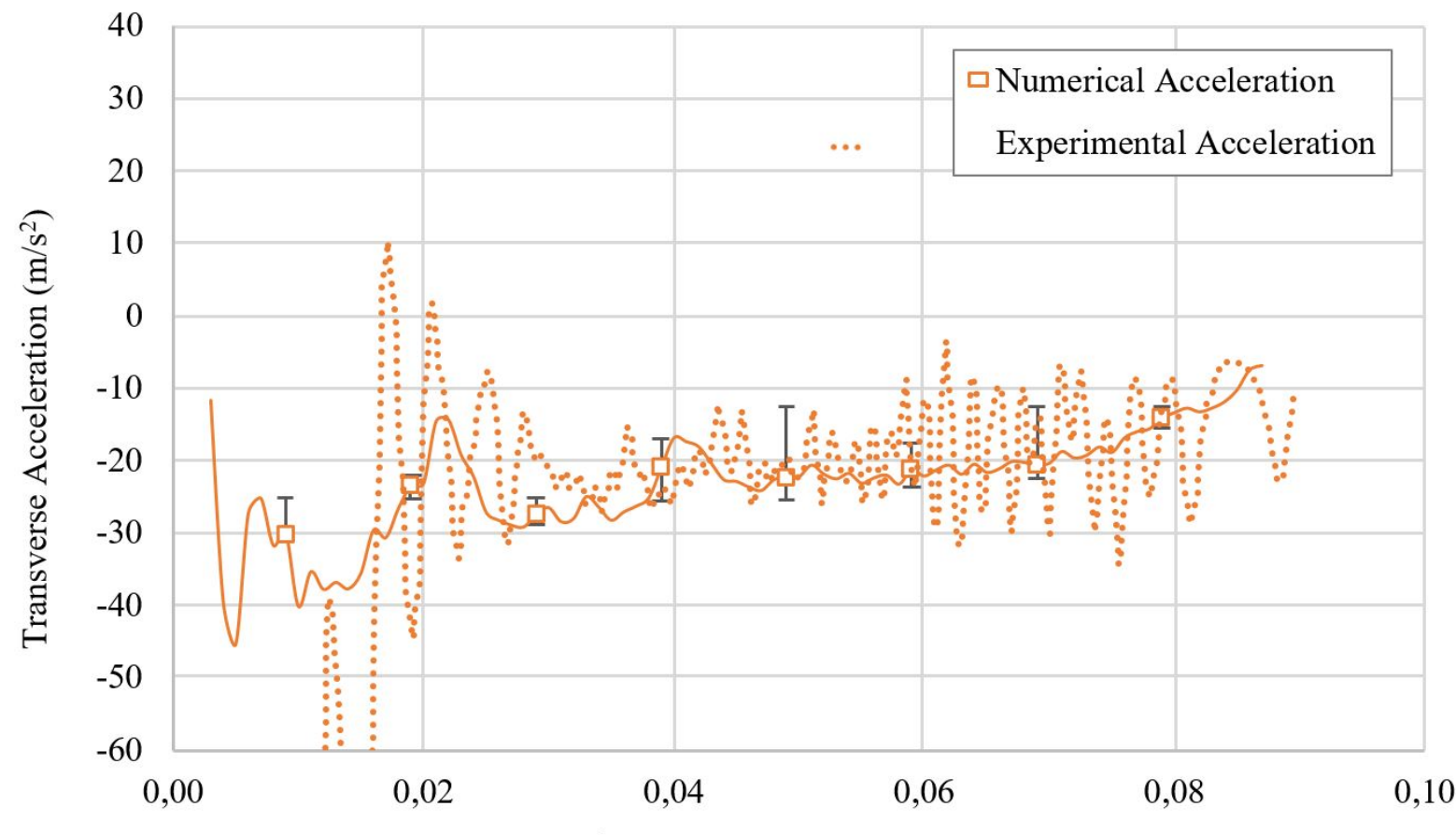

Time (s)

Figure 18: Graph showing the numerical versus experimental temporal acceleration histories of square tube drop test from a height of $250 \mathrm{~mm}$, with plotted friction coefficient of friction of 0.50 and error bar indicating the effect of changing the friction coefficient to 0.30 or 0.7 .

\subsection{PARAMETRIC STUDY}

There are many ways in which the side impact bars can be optimized; for example changes in materials and geometries. In this limited parametric study, the implementation of a tube-inside-tube configuration, as shown in Figure 19, was investigated and compared with the original design. The numerical beam model consisted of similar element formulations, material parameters, contact, boundary and initial conditions as developed in the original model. The mass of the compound tube was kept constant by varying the outer tube thickness with the inner tube length such that the mass of the compound tube was the same as the mass of the original tube, at $1.51 \mathrm{~kg}$. The maximum deflection of the compound tube was minimised by varying the inner tube length. The numerical solver LS-DYNA was coupled with the pre-processor ANSA CAE and the optimisation program LS-OPT. ANSA was used to perform geometric morphing of the tubes.

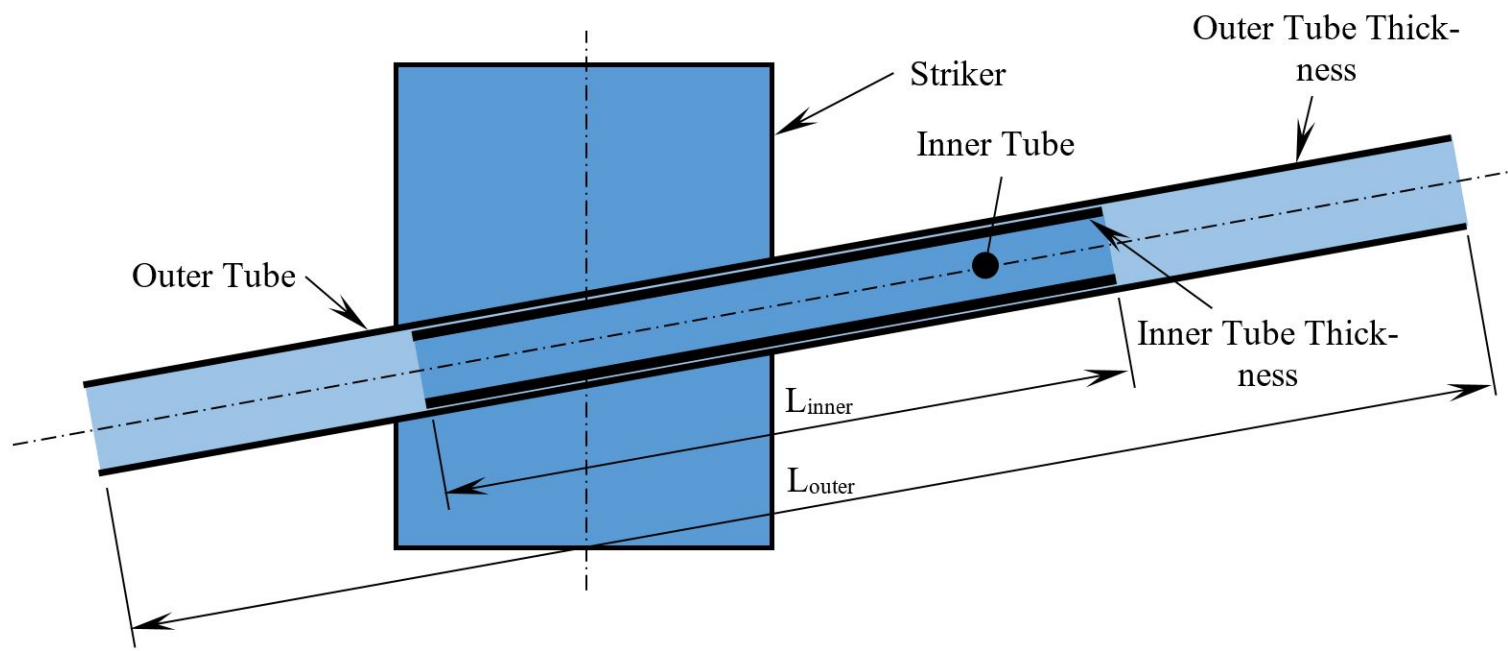

Figure 19: Illustration of compound tube configuration where inner tube has variable length and outer tube has variable thickness. 

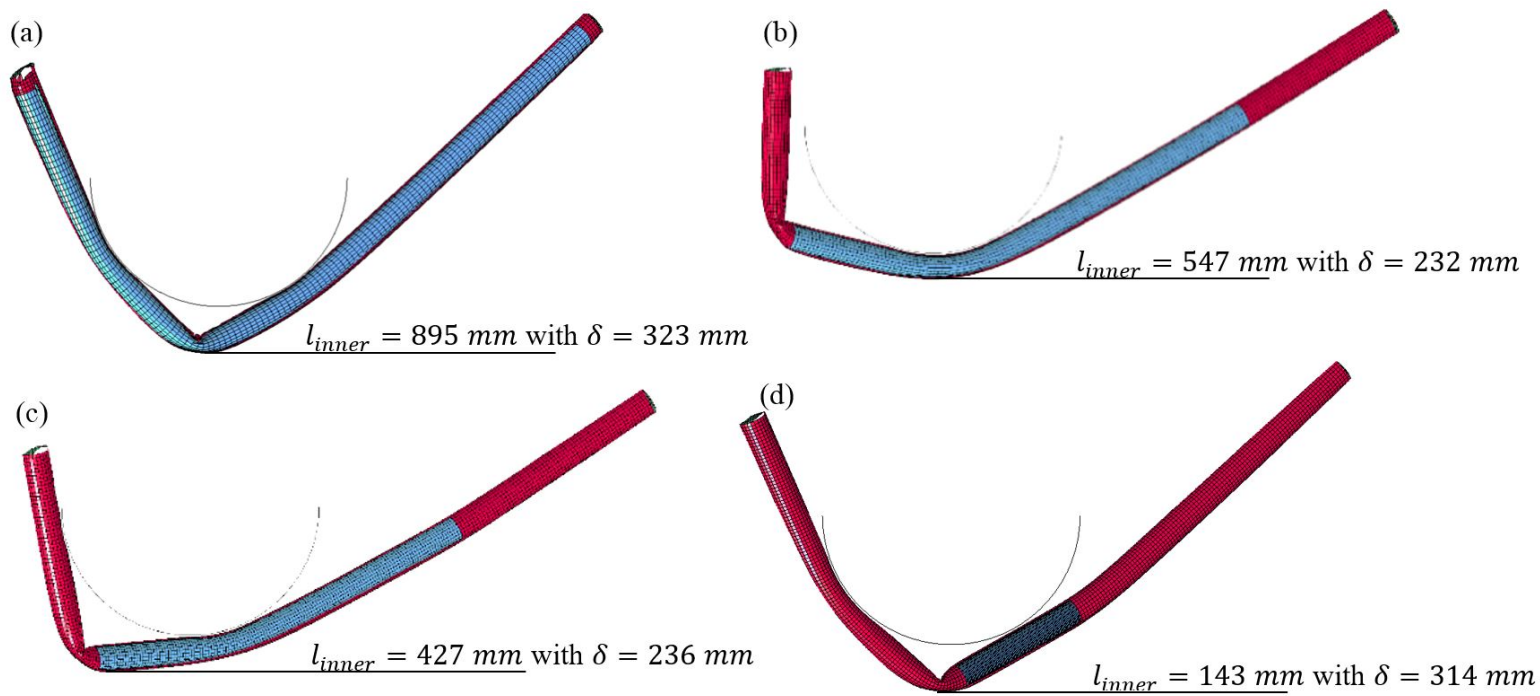

Figure 20: Effect of varying inner tube length with outer tube thickness.

Four samples from the results of the geometric optimisation study are shown in Figure 20. The transverse deflections were found to be greater than $300 \mathrm{~mm}$ when the inner tube did not extend over the buckling point and when the inner tube was greater than $800 \mathrm{~mm}$. This was due to the reduced amount of material available to absorb energy in the region of buckling. There was a length range of between $700-800 \mathrm{~mm}$ in which buckling occurred in 2 separate locations. The results are given in the chart shown in Figure 21.

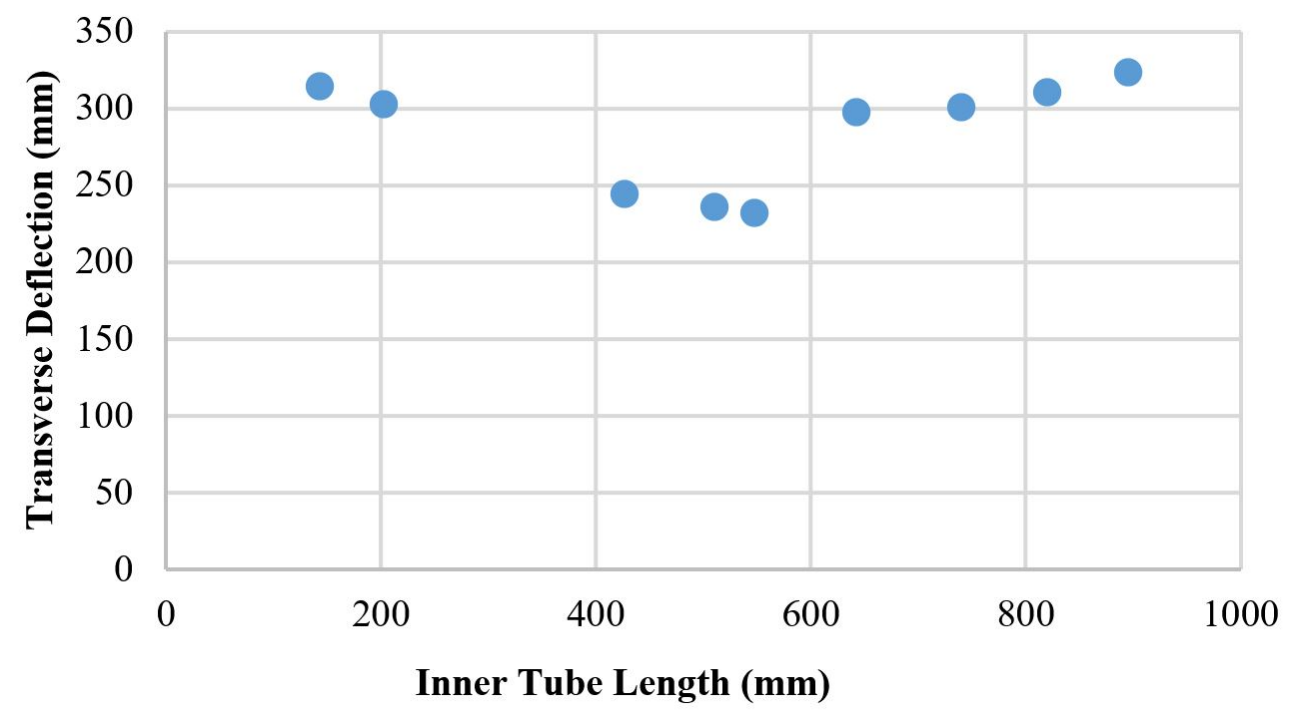

Figure 21: Graph of transverse deflection versus inner tube length for the compound tube configuration

Figure 21 shows that at both extremities of the tube length range the compound member did not perform well. The optimised tube configuration deformed by $232 \mathrm{~mm}$ which was a $26-28 \%$ improvement over the worst case. The driving factor behind the optimal point was largely affected by the position of the striking body. Results were optimised for the current configuration only.

The best tube configuration was added to the full vehicle model and rerun with the same settings as the original simulation. The rigid pole was found to intrude by $412 \mathrm{~mm}$ with the optimised configuration as compared with $413 \mathrm{~mm}$ for the original setup. Without the side impact beam, an intrusion of $438 \mathrm{~mm}$ was obtained. The original side impact beam in the full vehicle model absorbed approximately $8 \%$ of the total energy. As a result, a $10 \%$ improvement in the energy absorbing capability of the side impact beam correlates to a $0.8 \%$ improvement with respect to the full vehicle model. The overall improvement of $1 \mathrm{~mm}$ in terms of intrusion did not show great improvement in terms of energy absorption but indicated that there were possibilities to improve the crashworthiness of the side passenger door provided the optimization constraints were relaxed. 


\section{CONCLUDING REMARKS}

The effect of different configurations on the performance of a side impact beam from a passenger sedan car was investigated experimentally and numerically with a view to minimise intrusion into the passenger compartment. In this study a numerical model of a sedan car was subjected to a side pole impact, in close conformation to the FMVSS 214 standard. The door was then extracted from the full vehicle model and validated through experimentation, which was carried out in a vertical drop tester. A mass of $385 \mathrm{~kg}$ was dropped from a height of $1.274 \mathrm{~m}$ and found to cause a maximum deflection of $253 \mathrm{~mm}$ at 0.088 seconds after impact.

The side impact beam was identified as the single largest energy absorbing component to side impact protection, absorbing over $8 \%$ of the total energy. The beam was numerically extracted from the door model for optimisation. A limited parametric study was carried out on different tube configurations to determine the effect of length and thickness of a compound tube on the maximum transverse deflection in a lateral impact. The compound tube configuration in which the inner tube extended over the buckling point performed better than the single tube configuration. The result of the geometric optimisation of the side impact beam on the full vehicle model showed a $1 \mathrm{~mm}$ improvement over the singular configuration. The numerical work was successful in the optimisation study on the behaviour of a side impact beam in a lateral collision of a passenger sedan.

\section{Acknowledgements}

The financial assistance from the University of Cape Town's (UCT) postgraduate funding office and the John Davidson Educational Trust towards this research is greatly appreciated. The authors are grateful to the National Research Foundation (NRF) of South Africa for their financial support. Opinions expressed and conclusions arrived at, are those of the authors and not necessarily attributed to the UCT funding office nor John Davidson Educational Trust nor the NRF.

Author's Contributions: Conceptualization, CR Long; Investigation, CR Long and SCK Yuen; Writing - original draft, CR Long; Writing - review \& editing, SCK Yuen and GN Nurick; Co-supervision, GN Nurick; Supervision, SCK Yuen.

Editor: Marcílio Alves.

\section{References}

Blatz, P.J., Ko, W.L., (1962). Application of Finite Elastic Theory to the Deformation of Rubbery Materials. Transactions of the Society of Rheology 6, 223-252.

Fang, J., Gao, Y., Sun, G., Zhang, Y., Li, Q., (2014). Parametric analysis and multiobjective optimization for functionally graded foam-filled thin-wall tube under lateral impact. Computational Materials Science 90, 265-275.

Ghadianlou, A., Abdullah, S.B., (2013). Crashworthiness design of vehicle side door beams under low-speed pole side impacts. Thin-Walled Structures 67, 25-33.

Hallquist, J.O., (2006). LS-DYNA Theory Manual. Livermore Software Technology Corporation, Livermore, California.

IIHS, (2006). IIHS Side impact test program rating guidelines, Update November 2016 ed, Virginia: Insurance Institute for Highway Safety, Highway Loss Data Institute.

Jing, Y.-Y., Barton, D.C., (1998). The response of square cross-section tubes under lateral impact loading. International Journal of Crashworthiness 3, 359-378.

Lau, I.V., Capp, J.P., Obermeyer, J.A., (1991). A comparison of frontal and side impact: crash dynamics, countermeasures and subsystem tests, Proceedings of the 35th Stapp Car Crash Conference, San Diego, California, pp. 109-124.

NCAC, (2011). Development and Validation of a Finite Element Model for the 2010 Toyota Yaris Passenger Sedan (NCAC 2011T-001). National Crash Analysis Center, George Washington University, Virginia Campus, Ashburn, Virginia, Washington.

Otte, D., (1990). Comparison and realism of crash simulation tests and real accident situations for the biomechanical movements in car collisions, Proceedings of the 34th Stapp Car Crash Conference, Orlando, Florida, pp. 329-348. 
Otte, D., (1993). Deformation characteristics and occupant load capacity in lateral impacts for nearside belted front car passengers, Proceedings of the 37th Stapp Car Crash Conference, San Antonio, Texas, pp. 185-198.

Ramsdale, R., (2004). Engineer's Handbook: Reference Tables - Coefficient of Friction.

Strano, M., Villa, A., Mussi, V., (2013). Design and manufacturing of anti-intrusion bars made of aluminium foam filled tubes. International Journal of Material Forming 6, 153-164.

Sun, G., Tian, X., Fang, J., Xu, F., Li, G., Huang, X., (2015). Dynamical bending analysis and optimization design for functionally graded thickness (FGT) tube. International Journal of Impact Engineering 78, 128-137.

Teng, T.-L., Chang, K.-C., Wu, C.-H., (2007). Development and validation of side-impact crash and sled testing finite-element models. Vehicle System Dynamics 45, 925-937.

US Department of Transportation, N.H.T.S.A., (2016). Laboratory Test Procedure for FMVSS No. 201U, Occupant Protection in Interior Impact - Upper Interior Head Impact Protection, Office of Vehicle Safety Compliance, Washington, pp. 1-69.

WHO, (2014). The top 10 causes of death.

WHO, (2015). Global status report on road safety, Geneva, Switzerland. 